\title{
Research on Urban Smart Energy Evaluation Index System
}

\author{
Jun Tang, PengLing Li \\ School of Management, Xi'an University of Science and Technology,Xi'an, China
}

\begin{abstract}
On the basis of the development demand of smart city, combing the connotation of urban smart energy, combined with the goal of smart city development planning, the evaluation index system of scientific urban smart energy construction is constructed, and the basis of quantitative and qualitative analysis of smart energy construction is initially formed, which is helpful for urban planners to take control of the strength and direction of smart energy construction and provide reference.
\end{abstract}

\section{INTRODUCTION}

The intelligent construction of energy system plays a vital role in the realization of green, livable and highquality development in smart city and it is listed as one of the strategic plans also carried out in various smart cities actively. However, some problems have gradually been exposed, such as the blind copying of some smart energy projects it's deviance from the reality, including excessive pursuit of high-tech, largescale platforms and other hardware facilities, even some projects have stopped or stagnate, it cause the overall investment become large and slow. The root of these problems and phenomena lies in our lack of clear and specific understanding of the connotation and the goals of smart energy and also because of the lack of timely evaluation feedback mechanism, although related energy construction is involved in the evaluation index system of many smart cities. The indicators cannot systematically, scientifically and accurately reflect the level of smart energy construction, timely discover the mistakes in the construction of smart energy to regulate and constrain the direction of smart energy development. Therefore, it is extremely important to establish a set of evaluation index system for the level of urban smart energy construction.

At present, the research on smart energy is still in its infancy. The research on the evaluation of smart energy construction mainly has two sources: First of all, the evaluation of smart energy projects, but it mainly focus on micro-subjects, lacking objective and specific indicators. In April 2019, the National Energy Administration accepted the first batch of "Internet plus " smart energy projects from the implementation of the project, social benefits, project innovation, technical level of results and prospects for industrialization of results. The evaluation and acceptance of the project from experts is more subjective even though lacks the majority objective and specific indicators. Secondly, in view of evaluating smart cities, the research on the energy component in the evaluation index system of smart city construction is necessary, however, it is not scattered and can't form a systematic or comprehensive evaluation system. As mentioned above, the "Smart City Evaluation Index System 2.0" issued by the ShangHaipudong Smart City Development Research Institute covers intelligent energy management evaluation indicators, including the installation rate of household smart meters, the proportion of new energy vehicles and the proportion of building digital energy conservation. China's first national smart city standard "new smart city evaluation index" first-level evaluation indicators ecologically livable has an assessment of the city's green energysaving level, including indicators: 10,000 yuan GDP energy reduction rate, green building coverage rate and also focus on the online monitoring rate of energy units. The China-Singapore Tianjin Eco-City, which has been focusing on smart energy construction, the ChinaSingapore Standardization Research Institute, the Singapore-Singapore Public Affairs Cooperation Bureau and the ISO International Experts" "ChinaSingapore Tianjin Eco-City Smart City Indicator System" include indicators for smart energy evaluation. Public participation in the proportion of green behavioral intelligence systems and on-line monitoring management coverage of public building energy consumption distribution. It can be found that the evaluation of energy construction is indispensable when evaluating the construction of smart cities, but urban energy is also a relatively complex system. A few indicators are not representative and cannot truly measure the level of construction smart energy.

Through the relevant literature, we can find that on the one hand, we lack an evaluation index system which scientifically and systematically to reflect the level of intelligent energy construction and especially find the problems in time. Because of there are few studies on the evaluation of smart energy, the existing research is mainly aimed at individual projects, failing

\footnotetext{
* Corresponding author:940161863@qq.com
} 
to reflect the goal of smart energy service in smart cities and lacking a objective and systematic evaluation system. On the other hand, our measurement of the degree of "wisdom" is rather vague. Analysis of existing indicators found that the degree of wisdom is measured by the application rate of various technologies and products, the goal of energy construction is also directed to the application of new technologies, while ignoring the essential objectives of serving urban residents. Perhaps the understanding of the connotation of urban smart energy is not in place and the understanding of the ultimate goal of its construction is vague and cannot play a guiding role. Therefore, on the basis of correct interpretation of the connotation of smart energy and clear construction goals, the establishment of a smart energy evaluation index system can better grasp the development level of smart energy for decision-making institutions, thus making more scientific and rational planning decisions. For the relevant implementing agencies, the smart energy rating indicator can be used to correctly assess the construction project to find the inadequacies and correct them in time, so as to ensure the construction of smart energy is fast and healthy, and truly serve the development of smart cities. The future development of the city has extremely important practical significance.

\section{URBAN WISDOM ENERGY CONNOTATION}

At present, all of the research on the concept of smart energy in China, the wisdom energy proposed in the "Guiding Opinions on Promoting the Development of "Internet plus" Smart Energy" is more authoritative and based on the power system, it builds an energy Internet that accesses multiple energy sources, which aims to multi-source complementarity, vertical "sourcenetwork-load-storage" coordination, highly integrated information development and energy transformation development to build a new intelligent energy system horizontally, its definition of smart energy concept is from the perspective of the entire energy industry and focuses on technical applications.From the perspective of urban development admitted, there is still no unified definition of smart energy, but basically the following three points of consensus have been reached:

Smart energy can effectively solve the energy and environmental problems facing cities and meet the needs of smart cities for low-carbon green development. In the construction of smart cities, urban energy consumption is one of the key issues to be concerned. Governments regard smart, green living, energy efficiency's improving, and environmental protecting as the top priority of smart city construction and also hope to making progress to build urban wisdom,means the sustainable development of the city. Smart energy use modern science and technology to create green energy supply and low-carbon energy consumption, to solve the energy and environmental problems encountered in the development of smart cities and to meet the development needs of smart cities for green and low-carbon.

Smart energy's intelligent construction of energy infrastructure can guarantee the city's energy security needs and provide more refined services to urban residents. In the intelligent construction of smart cities, the aging energy infrastructure cannot meet the energy demand of urban development. The State Council issued the "National New Urbanization Plan (20142020)" mentioned that smart technology in the key application areas of smart cities has mentioned the intelligent construction of infrastructure such as electricity, transportation, and pipe network. Intelligently transform existing energy facilities, provide energy infrastructure that is compatible with urban development and provide cities with both energy security and more refined energy services.

The construction of smart energy information can promote the coordination and complementarity of regional energy resources, also meet the needs of smart city information construction. Smart cities use information technology to meet the automation better,intelligent needs of urban operation, management and service. In the process of information construction, they need data on environment, energy and transportation to build smart city spatio-temporal information cloud platform. Excavation reveals the characteristics of temporal and spatial changes in the data, providing the primary data and decision-making basis for urban managers to develop, construct, manage and formulate the city. The informationization of energy system is an important part of intelligent city information construction. It is also the main content of urban smart energy construction.

Therefore, based on the existing concept of smart energy given from the perspective of technology application, we combed the demand for energy construction in smart cities and concluded the concept of urban smart energy from the perspective of smart city development needs. We things that energy refers to the construction of an energy system that uses green energy, green energy production, low carbonization, energy service refinement and energy informationization through the use of a new generation of information technology it builds a smart energy system that can guarantee the efficient operation of cities and serve smart cities.

\section{CONSTRUCTION OF URBAN SMART ENERGY EVALUATION INDEX SYSTEM}

Establishing an evaluation system that reflects the level of urban smart energy construction has important practical significance for urban managers to change from the qualitative evaluation of smart energy construction level to quantitative evaluation. It is not only conducive to the indexing, quantification, stratification of the urban smart energy construction but also making the evaluation results more objective and true. There are also horizontal and vertical 
comparisons among urban decision makers to find gaps and predict future trends.

\subsection{Selection of Urban Smart Energy Evaluation Indicators}

Starting from the meaning of the concept of urban smart energy, according to the principles of operability, science, comprehensiveness and economy, the

Table 1 Index selection of urban intelligent energy evaluation index system

\begin{tabular}{|c|c|c|}
\hline $\begin{array}{c}\text { Primary indicator } \\
\text { Secondary indicators } \\
\text { Three-level indicator }\end{array}$ & Secondary indicators & Three-level indicator \\
\hline \multirow{13}{*}{$\begin{array}{l}\text { Energy production } \\
\text { greening A }\end{array}$} & \multirow[t]{3}{*}{ Energy supply $A_{1}$} & $A_{11}$ city unit area renewable energy installed capacity \\
\hline & & A12 power consumption coal consumption level \\
\hline & & A13 peak and valley fluctuation range \\
\hline & \multirow[t]{2}{*}{ Energy structure $\mathbf{A}_{2}$} & A21 proportion of clean energy in primary energy \\
\hline & & A22 Renewable Energy Acceptance \\
\hline & \multirow[t]{2}{*}{ Environmental quality $\mathbf{A}_{3}$} & A31 unit GDP carbon dioxide emissions \\
\hline & & A32 unit GDP pollutant emissions \\
\hline & \multirow[t]{6}{*}{ Energy consumption $\mathbf{B}_{1}$} & B11 unit GDP energy consumption level \\
\hline & & $B_{12}$ key high energy-consuming industry unit capacity energy \\
\hline & & $B_{13}$ unit construction area energy consumption level \\
\hline & & $B_{14}$ public transportation share \\
\hline & & $B_{15}$ new energy vehicle penetration rate \\
\hline & & $B_{16}$ electrical energy accounts for the proportion of terminal en \\
\hline \multirow{9}{*}{$\begin{array}{l}\text { Low Carbonization of } \\
\text { Energy Consumption B }\end{array}$} & \multirow{6}{*}{ Energy efficiency $B_{2}$} & $B_{21}$ unit GDP energy consumption reduction rate \\
\hline & & $\begin{array}{l}\text { B }_{22} \text { key high energy-consuming industry unit production value } \\
\text { decline rate }\end{array}$ \\
\hline & & $B_{23}$ local one-time energy utilization efficiency \\
\hline & & $B_{24}$ external input energy utilization efficiency \\
\hline & & $B_{25}$ user energy cost reduction rate \\
\hline & & B26 energy's Recyclability \\
\hline & $\begin{array}{l}\text { EnergyFacility Information } \mathrm{C}_{1} \\
\text { Infrastructure } \mathrm{C} 1\end{array}$ & $\mathrm{C}_{11}$ gas penetration rate \\
\hline & & $\mathrm{C}_{12}$ grid reliability rate \\
\hline & & $\mathrm{C}_{13}$ number of charging piles per unit area \\
\hline \multirow{8}{*}{$\begin{array}{l}\text { Informatization of } \\
\text { Energy Facilities C }\end{array}$} & & $\mathrm{C}_{14}$ per capita power capacity \\
\hline & & $\mathrm{C}_{15}$ smart meter penetration rate \\
\hline & \multirow[t]{4}{*}{ Technical application $\mathrm{C}_{2}$} & $C_{21}$ energy related patent grant amount \\
\hline & & $\mathrm{C}_{22}$ Smart Energy Demonstration Project Data \\
\hline & & $C_{23}$ energy sensor penetration rate \\
\hline & & $\mathrm{C}_{24}$ energy data openness \\
\hline & \multirow[t]{2}{*}{ Energy Management $D_{1}$} & D energy service platforms \\
\hline & & $D_{12}$ energy management assessment mechanism \\
\hline \multirow{4}{*}{$\begin{array}{c}\text { Refinement of energy } \\
\text { services D }\end{array}$} & \multirow{4}{*}{ Energy Service $\mathbf{D}_{2}$} & D13 urban energy planning integrity \\
\hline & & D21 user satisfaction \\
\hline & & D22 emergency demand response time \\
\hline & & D23 public participation \\
\hline
\end{tabular}

(1) Green production of energy production selection of indicators can be selected from the green energy production, the low carbonization of energy consumption, the informationization of energy equipment and the refinement of energy services. Obtain the indicator system as shown in Table 1. Here's the following brief description of the connotation according to each indicator.

(1) Green production of energy production 
The intelligent construction of urban energy needs to start from the energy production link. There are also huge gaps between different energy production costs and the pollution generated. The smart city's demand for energy production is not only the need to ensure energy supply but also the need to optimize energy structure protection and the impact of energy production on the environment. Therefore, the choice of energy supply, energy structure and environmental quality as secondary indicators.

(2) Low carbonization of energy consumption

The city is one of the important subjects of energy consumption, so it is also an important part of smart energy construction. In order to realize the construction goal of smart construction environment-friendly city, it is necessary to start intelligent construction from energy use, not only to reduce the unnecessary energy consumption, what's more important is to improve the efficiency of urban energy use, so the choice of energy consumption and energy efficiency are both the secondary indicator.

(3) Informationization of energy facilities

The information construction of urban energy facilities is the main part of the development of smart energy technology. In the information construction of smart cities, the construction of energy facilities is an important part. The construction of information facilities is an important basis for realizing intelligence. The application of facilities and related technologies is a secondary indicator to evaluate the level of urban smart energy construction.

(4) Refinement of energy services

The goal of urban smart energy construction is to serve urban residents. The goal of smart city construction is to provide more convenient life for urban residents. The refinement of energy services is also an important component. Therefore, relevant indicators of energy management and energy services are selected.

\subsection{Indicator weight determination}

The analytic hierarchy process uses a certain standard to objectively quantify the subjective judgment of the person. The urban intelligent energy construction evaluation uses the analytic hierarchy process to quantitatively analyze and provide a quantitative basis for decision-making. The method needs to check perform consistency during it uses. If it does not pass the test, it needs to be re-discussed by experts and scholars until the test passes. Therefore, the method has the advantages of reducing subjective interference, correcting inconsistent views and convenient calculation. Suitable for the current evaluation of urban smart energy construction.

First, the urban smart energy evaluation system is divided into three levels, generally the target level, the criterion level and the criterion level. Secondly, the pairwise comparison is performed and the judgment matrix is obtained as $C=\left(c_{i j}\right)_{n \times n}$, where $c_{i j}$ represents the importance of the factor $i$ and the factor $j$ with respect to the target. Finally, the judgment matrix consistency test is expressed by the random consistency ratio $C R$, which is calculated by the ratio of the judgment matrix consistency index $C I$ to the average random seborrheicity index $R I$. If $C R<0.1$, the judgment matrix has Relative consistency, otherwise it will need to continue to adjust to guide the satisfaction of the conditions.

Through the evaluation of the relevant scores of the indicators for urban smart energy construction, the following results were obtained through calculation.

Table 2 Judgment matrix $T$ results

\begin{tabular}{lcccccc}
\hline \multicolumn{1}{c}{ Judgment matrix } & $\begin{array}{c}\text { A green } \\
\text { energy } \\
\text { production }\end{array}$ & $\begin{array}{c}\text { B energy } \\
\text { consumption is } \\
\text { low } \\
\text { carbonization }\end{array}$ & $\begin{array}{c}\text { C energy } \\
\text { facility } \\
\text { information }\end{array}$ & $\begin{array}{c}\text { D energy } \\
\text { service } \\
\text { refinement }\end{array}$ & $W_{i}$ & $\begin{array}{c}\text { Consistency } \\
\text { result }\end{array}$ \\
\hline $\begin{array}{l}\text { A green energy production } \\
\text { B energy consumption is low }\end{array}$ & 1 & $\mathbf{0 . 3 3 3 3}$ & 2 & $\mathbf{0 . 2 5}$ & $\mathbf{0 . 1 2 1 6}$ & CR=0.0806 \\
carbonization & 3 & 1 & 0.3333 & 0.25 & 0.2374 \\
C energy facility information & 0.5 & 3 & 1 & 0.25 & 0.0866 \\
D energy service refinement & 4 & 4 & 4 & 1 & 0.5544 \\
\hline
\end{tabular}

According to the above steps, the modules are calculated and tested layer by layer and the weight of each element relative to the previous layer is obtained, then the layer-by-layer calculation is

performed, the index values are multiplied by the weight values to obtain a comprehensive score and the city is calculated. The weight of the evaluation index of smart energy construction (Table 3).

Table 3 Evaluation index system and weight distribution of urban smart energy construction

\begin{tabular}{llllll}
\hline $\begin{array}{c}\text { Primary indicator } \\
\text { Secondary } \\
\text { indicators } \\
\begin{array}{c}\text { Three-level } \\
\text { indicator }\end{array}\end{array}$ & Level & Secondary indicators & Three-level indicator & Level \\
\hline Energy production & 0.12 & Energy supply A & & \\
\hline
\end{tabular}


greening A

Energy structure A2

Environmental quality $\mathrm{A}_{3}$

0.23 Energy consumption $B_{1}$

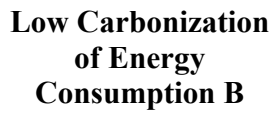

Energy Facility Information $C_{1}$

Informatization of Energy Facilities C

Technical application $\mathrm{C}_{2}$

0.55 Energy Management $D_{1}$

Refinement of energy services D Infrastructure C1

Energy efficiency $B_{2}$

Energy Service $D_{2}$
A12 power consumption coal consumption level

A21 proportion of clean energy in primary energy

A22 Renewable Energy Acceptance

0.18

A31 unit GDP carbon dioxide emissions

0.21

$A_{32}$ unit GDP pollutant emissions

0.17

$B_{11}$ unit GDP energy consumption level

0.14

$B_{13}$ unit construction area energy consumption level

$B_{14}$ public transportation share

0.16

$B_{15}$ new energy vehicle penetration rate

0.11

$B_{21}$ unit GDP energy consumption reduction rate

0.09

0.09

$B_{22}$ key high energy-consuming industry unit production value decline rate

0.11

$B_{23}$ local one-time energy utilization efficiency

B26 energy's Recyclability

0.14

$C_{11}$ gas penetration rate

0.16

$\mathrm{C}_{12}$ grid reliability rate

0.14

$C_{13}$ number of charging piles per unit area

0.21

$\mathrm{C}_{14}$ per capita power capacity

0.08

$\mathrm{C}_{15}$ smart meter penetration rate

0.11

$C_{21}$ energy related patent grant amount

0.05

$\mathrm{C}_{22}$ Smart Energy Demonstration Project Data

0.16

$\mathrm{C}_{24}$ energy data openness

0.14

$D_{11}$ energy service platforms

0.11

D13 urban energy planning integrity

0.18

$D_{21}$ user satisfaction

0.18

0.18

$D_{22}$ emergency demand response time $\quad 0.28$

$D_{23}$ public participation

0.18

and to provide government with standard evaluation of smart energy construction research foundation.

\section{REFERENCES:}

1. P. Ahern, P. Deane, T.Persson.A perspective on the potential role of renewable gas in a smart energy island system . Renewable Energy .15,8(2015)

2. Energy quality management for building clusters and districts (BCDs) through multi-objective optimization[J] . Hai Lu, Kari Alanne, Ivo Martinac. Energy Conversion and Management . 68,7(2014)

3. Applying a multi-objective optimization approach for Design of low-emission cost-effective dwellings [J] . Mohamed Hamdy, Ala Hasan, Kai Siren. Building and Environment . 35,1(2011)

4. Huang Xiaoli, Li Zhenjie, Zhang Wei, Gu Han, Chen Guodong, Zong Zhigang, Duan Wei. Energy 
Development Demand and Smart Grid

Construction under the New Situation[J]. China

Electric Power, 2017, 50(09): 25-30. 